\title{
NA MORTE DO POETA SAINT-JOHN PERSE
}

- Homenagem Postica -

\section{Jaime Fornandes}

\section{EXILIO $-1 \cdot$}

"Portas abertas por sobre as areias, portas abertas para o exílio,

$E$ as chaves entregues aos vigias, e $O$ astro anelante sobre a soleira:

Hóspede, deixa-me a fua casa de vidro sobre as areias...

E ○ Verão de gipso aguça seus ferros de lança an nossas chagas,

E eu elejorum lugar flagrante e nulo como ossário de estaçōes,

E, sobre todas as proies do mundo, o esplrito dos deuses fumegantes deserta sua camada de amianto.

E os espasmos do relámpago são para o éxtase dos Príncipes em Táurida."

$$
-x-x-x-
$$

A poesia de Saint-John Perse é um lugar de exilio, condição humana absoluta e constante, solidão desenraizada, metamorfose, transmutação do Homem na palavra. O exillio é um Humanismo (os deuses fumegantes) movediço (as areias as praias, as estaçōes, - Verão de gipso), onde nunca se chega a entrar (nunca se passa da soleira), ainda que Príncipe, como Saint-John Perse o foi - dos Poetas e pelo nascimento ruma pequena ilha das Antilhas Francesas, a ilha encantada e cantada Saint-Léger-les-Feuilles.

Poesia, Canto metamorfoseado em desenraizamento metropolitano, mais novaiorquino.

Poesia, canto de Aves solitárias em peregrinação -

... "a mesma gaivota em sua osa

a mesma gaivota em seu ninho,

voando velozmente

ligando as estáncias do exílio..."

- Traduçáo do original francès de PERSE nor Jaime FERNANDEB. 
Poesia do Tempo, das Estações (As Chuvas, As Neves), Mutação-Transmutaçāo, longínqua, de Poetas em Príncipes, em voz que é palavia cristalina ("le mot rare").

Poesia da limpidez, onde as aves (Les Oiseaux) constantemente ligam estâncias do exilio, mas também do poema, em equivalências que só encontram paralelo no Georges Braque dos últimos trabalhos.

As aves que the surgiram um dia nos Pireneus, na figura de um espécime raro, o Tichodroma muraria (rosa dos Alpes), nas asas da criação contemporânea de Debussy e de Vicente d'Indy, da amizade de Paul Claudel e André Gide (que the publica os Eloges em 1911, um ano depois da sua licenciatu:a em Direito).

As aves, que o levarão, qual exilado, às mais iongínquas partes do mundo em missão diplomática.

O Crusoé dos Eloges é a sua primeira imagem da solidão (e do exílio):

"Crusoé! esta noite perto da tua ilha o céu que se aproxima louvará o mar, e o silêncio multiplicará a exclamação dos astros solitários."

Solidão, densenraizamento, nostalgia da Guadalupe distante e antepassada, tema comum da geração seguinte em: Aimé Césaire, também antilhano (da Martinica), no Cahier d'un Retour au Pays Natal; León Damas (Guiana Francesa), no Retour de Guyanne; Léocold Senghor (Senegal), nos Chants pour Naett.

$$
-x-x-x-
$$

Saint-John Perse pertence à categoria de Homens-Duplos, ne sentido que the dá $A$. Artaud/B. Brecht.

Embora toda a sua poesia seja uma "exper ência vivida", nunca ele consentiu que a sua vida pública fosse objecto de comparação com a sua obra poética. Significa que o homem-Alexis Léger nada tem de comum com o poeta-Saint-John Perse. Significa alienação do Homem que a ultrapassa, não fugindo ao real, mas construindo um outro real/significante, cujo grau de autonomia se alicerça num vocabulário sotalmente transfigurado que alimenta as suas significaçōes internas. 
O tempo de Alex's Léger é o tempo da decadência francesa, o tempo de Aristide Briand, com o qual se identifica politicamente e do qual foi o homem de confiança.

Durante vinte anos foi ele quem praticamente dirigiu a política externa francesa, de seu bureau do Quai d'Orsay. E é perante a grande ruptura de $\mathbf{4 0}$ que o Diplomata ganha consciência da alienação ("Plus vous avez et moins vous êtes" - citaçāo de Roger Garaudy).

O Homem total, da esperança dos Eloges, na sua grande alegria de viver, torna-se, transforma-se no Homem alienado, complementar na negação e na revolta do seu humanismo ateu do Exil. Só depois de muito amarmos podemos destruir: mar/amor, identificação total, do Homem sem limites, do universo paralelo do sonho tornado real, do homem que se faz a ele mesmo através da linguagem.

Poeta épico, sem dúvida; épico através de todos os climas, das viagens ininterruptas, das civilizaçōes desaparecidas.

Construçào de um Todo que se identifica com o Mundo ao qual nunca deixou também de pertencer ("il faut qu'il soit UN avec le TOUT").

Ascese do Exllio, que atinge a condição própria da linguagem transmudada em VOZ de toda a HUMANIDADE.

Eis os limites/ilimitados da sua Poesia. 


\title{
RESPOSTA A "ARTE DE ARMAR"
}

Jurll Campolo

\author{
Sim, Poeta, \\ há sempre estirpe de fênix \\ na ponta de tua língua - \\ enquanto cismo auto-consumida \\ caio na armadilha do discurso. \\ Agarro como posso o \\ fio do poema \\ que ressoa em vastos \\ horizontes reprimidos \\ tecidos pelo avesso \\ aléth e aquém da noite. \\ E da lavra que tu sabes \\ que sei eu? \\ Que sei da língua e \\ da linha que deleitam? \\ Não moro no recinto \\ das essências \\ mas participo ativamente \\ da derradeira \\ epifania do universo. \\ $E$, se, neste momento, \\ as coisas acontecem \\ em nós e além de nós, \\ discretamente, \\ joguemos com palavras \\ e silêncios 0 inútil jogo \\ do lugar-comum. \\ Inscrevamos nomes sobre mares \\ declinemos odes e sonetos \\ mulfipliquemos setes nos espelhos \\ Enunciemos, comutemos \\ que o sentido foge pela \\ fresta aberta pelo corte \\ epistemológico.
}




\section{MADRUGADAS O LIUVIAS}

Ciérnense las madrugadas por la Tierra destiladas sin intención de astros mudos y cubran las ciudades pétreas de los hombres.

El hombre duerme.

Velan ellas su destino

que se trama ignorado, tela de insectos terrestres

entre torres de cemento y campos de asfalto.

El despertar de la luz corta la urdimbre.

Bracea el hombre hacia la superfície

muévese hacia su vida sin pregunta mientras

acechan las madrugadas al planeta.

¿Y qué es la vida?

Aterrador soledad pluvial llamando a las ciudades del mundo, las lluvias bajan sus dedos ávidos hasta la tierra.

Maravilla en movimiento, conclaman luces mortecinas, noches,

trabajos se suceden entre las letargias del hombre.

[negras,

La lluvia labra y labra su astro ciego

hasta arrancar la secreta respuesta.

Entonces repliega su asombrosa mano. 


\section{S A RTREAN A}

\section{Miguelina Soifer}

Sólo el no ser

redimirá el fulgor

de ser

humano.

Invertida se hará la trayectoria

de tal mariposa extraña:

libélula transgredida por el ala de luz

hacia el ge.men grisáceo de su larva.

Letargo, inanidad, rigidez, abulia,

¿pagarán la pedrería del vivir?

La pedrería viva del vivir:

rubi de pensar,

ágata de sentir,

esmeralda de soñar

topacio, carbunclo de querer legar.

Sólo el no ser

redimirá el fulgor de ser

humano.

Pero la sarta triste y matizada

de las cuentas de melancolía,

lágrima soledad, ansiedad, angustia,

- el inocente nervio castigado

en el contorno cárneo de la criatura?

Sólo el no ser redimirá el dolor

de ser

humano. 


\section{Sigrid Renaux}

\section{MAR-POEMA}

(5. - lugar no concurso de poesia promovido pela Academia de Letras José Alencar e Centro de Letras do Paraná $-27 / 6 / 80$ )

$$
1-
$$

na tarde suave do mar sigo o roteiro das conchas indecifráveis signos profundos das águas

na tarde stegre do mar ouço ecos de vagas imprescrutáveis acalentos e risos de crianças

quebrando na praia

na serena tarde do mar as nuvens refletem os indefiniveis sonhos das ondas e as cores e cantos do oceano convergem trans-bordando re-criando na areia o marpoema

$$
11-
$$

Pretinho passando na praia levando tosco carrinho de mão coberto de alegres latas vazias, pequenas, grandes, coloridas.

Pretinho passando na praia empurrando feliz seu carrinho de mão, marcando ao longo da areia tão branca a passagem pura e alegre da vida.

$$
\text { III - }
$$

sob o silêncio verde da madrugada

repousa o canto dos pássaros - 
harmonias da natureza, sons suspensos

pairam nas folhas atentas -

melodias se cruzam e se esvaem

ecoando ao longo dos instantes oníricos

da manhã -

acordando-me

$$
\text { IV - }
$$

nova

mente

mar: imponderóvel

mente

novo

V -

pássaros marinhos

barcos distantes

emergem - submergem nas ondas

$$
\text { VI - }
$$

azul-marinho

revolto azul-onda

profundamente

branco

$$
\text { VII - }
$$

es puma

pluma flutuante

instante

in constante

antes

ex pluma

superficie

à

jorram irrompem

cintilantes deslumbrantes

ascendem sobem

extáticos enlevados

de cristais de luz

miríades centelhas

sons melodias

submarinos submersas 


$$
\text { IX - }
$$

$$
\begin{gathered}
\text { conch } \\
\text { cheia de mor } \\
\text { e de areia } \\
\text { conténs } \\
\text { em teu horizonte } \\
\text { o mundo } \\
\text { enclausurado } \\
\text { equilibrado } \\
\text { refletido }
\end{gathered}
$$

$$
x-
$$

nos degraus da areia espelhos dágua:

fragmentos de sol refletidos

$$
\text { XI - }
$$

\section{Sinuoso}

insinuante

Sopro do vento

no mar

repouso-instante

das ondas

ouvindo seus ecos

no ar

$$
\text { XII - }
$$

nuvens desfazem constelaçōes:

surgem formas novas,

linhas não mitológicas -

impassiveis,

as estrelas não registram o fato

$$
\text { XIII - }
$$

jordins antigos -

perfumes verde-musgo

em péfalas de vidro 


$$
\text { XIV - }
$$

sol

dissolve mil verdes em ouro

inunda os campos de veräo

esparrama nas nuvens pintadas

imagens impregnadas de luz

$$
\text { XV - }
$$

buscar a paisagem oculta

além da grande sombra verde das árvores -

reflexos escuros em vidros d'água -

relva sol-luz,

campo se eleva à nuvem

horizonte tocando numa flor

$$
\text { XVI - }
$$

mar pleno, saturado, transbordando

mansamente: maré cheia

$$
\text { XVII - }
$$

mar - manhã

brilhante de sol - coral:

surgem estrelas,

conchas rajadas reluzem na areia

\section{XVIII -}

nas entrecortadas linhas da praia

o mar desenha sua estória:

sempre inter-rompida

sempre a se re-fazer

sempre a se trans-formar -

onda contra onda, verde contra azul, espuma contra espuma,

signo enigma de um canto-encanto

forma flutuante do enlace indefinivel

das águas e da areia 